\title{
Treating uterine synechiae with human amniotic membrane graft
}

\author{
Siddhartha Chatterjee ${ }^{1}$, Bishista Bagchi ${ }^{2}$, Arpan Chatterjee ${ }^{3}$ \\ ${ }^{1}$ Director, Calcutta Fertility Mission, 21 Bondel Road, Kolkata \\ ${ }^{2}$ Clinical Associate, Calcutta Fertility Mission, 21 Bondel Road, Kolkata \\ ${ }^{3}$ Specialist Consultant, ESI Hospital, Kolkata
}

*Corresponding author: Dr. Siddhartha Chatterjee, Calcutta Fertility Mission, 21 Bondel Road, Kolkata; Tel: 9830387875; E-mail: sidchat54@gmail.com;

Received: February 04, 2020; Accepted: February 14, 2020; Published: February 24, 2020;

\begin{abstract}
Objective: To determine if placement of a human amniotic membrane graft at the time of hysteroscopic intrauterine adhesiolysis will promote regeneration of the endometrium in women with secondary amenorrhea and infertility. This case-series evaluated the use of human amniotic membrane graft in women with secondary amenorrhea and who had a desire for future fertility. Results: Five women received the amniotic membrane graft between 2015-2019. Four of the five women had secondary amenorrhea and one had scanty periods prior to the surgery (post suction and evacuation procedure due to spontaneous miscarriage), and all of the women achieved menstruation post-operatively. Two of them achieved pregnancy.
\end{abstract}

Conclusion: This procedure may provide an alternative treatment option for patients with uterine synechiae who desire future menses and pregnancy.

\section{Introduction}

Women usually present with secondary amenorrhea, infertility, or recurrent pregnancy loss in cases of uterine cavity synechiae [1]. Intrauterine adhesions are most commonly caused by a dilation and curettage $(\mathrm{D} \& \mathrm{C})$ procedure for medical termination of pregnancy or spontaneous abortion or latent genital tuberculosis, as in case of our patients. The risk of intrauterine adhesions after one or two D\&C's is about $14-16 \%$; severity of adhesions also increases with repeated D\&C [2]. Operative hysteroscopy with lysis of intrauterine adhesions is a viable treatment option. Hysteroscopic adhesiolysis can be performed using scissors, cautery or laser vapourization [3-5]. However, with all forms of adhesion resection, there is a high rate of recurrence of intrauterine adhesions ranging between $3.1 \%$ and $23.5 \%$. [1] Due to the high rate of intrauterine adhesion formation, many procedures have been attempted to reduce it. An unique technique has been performed by few authors in which was they had used a fresh amnion graft over an inflated balloon or a Foley catheter for 2 weeks at the time of adhesiolysis in women with moderate and severe intrauterine adhesions and there was significant improvement in uterine length and intrauterine adhesions [6]. Our study is a case-series evaluating the use of human amniotic membrane graft to reduce adhesion formation, promote mesenchymal stem cell growth, evaluate for a thickened endometrial stripe and subsequent pregnancy in patients with secondary infertility.

\section{Materials and Methods}

Five infertile women of age 28-32years, who presented to Calcutta Fertility Mission between 2015-2019 with secondary amenorrhea, diagnosed by transvaginal ultrasonography 9 thin endometrium with glistening structure) and hysterosalpingogram, were informed that the placement of a human amniotic membrane graft will be done for regeneration of the endometrium. Latent genital tuberculosis was ruled out by DNA-PCR of pre- menstrual endometrial aspirate. After informed consent was obtained, five women underwent operative hysteroscopy, lysis of intrauterine synechiae and curettage. A $3.5 \times 3.5 \mathrm{~cm}$ amniotic membrane graft was wrapped around a curette (Size 8) and inserted into the uterine cavity in three women. In another two cases the graft was put in the cavity using sinus forceps. After insertion, the graft was adjusted and excised at the level of the cervix. Routine antibiotics were prescribed for all patients and Estradiol Valerate (2mg) was given for the next three months. All five women had regular menstrual cycles after 3 months, ET (endometrial thickness) was assessed on $10^{\text {th }}$ day and $12^{\text {th }}$ day of the menstrual cycle and were found to be satisfactory. ( ET on $10^{\text {th }}$ day -6 to $7.5 \mathrm{~mm}$; on $12^{\text {th }}$ day -8 to $9 \mathrm{~mm}$ )

\section{Results}

Five women received the human amniotic membrane graft between 2015-2019. All of them had amenorrhea prior to the surgical procedure (ranging from 3-8 months of amenorrhea), and all had achieved menstruation post-operatively. There is no universal grading system for the severity of intrauterine adhesions, the severity was graded using the Valle and Sciarra's 1988 classification. Three of five women had moderate synechiae and two of them had severe form of synechiae. Mild disease indicates flimsy adhesions composed of basal endometrium producing partial or complete uterine cavity occlusion. Moderate disease involves fibromuscular adhesions that are characteristically thick, covered by endometrium that may bleed 
with partial or total occlusion of the uterine cavity. Severe disease is composed of connective tissue with no endometrial lining and partially or totally occlude the endometrial cavity. There were no postoperative complications.

Two of the five women achieved pregnancy. The first patient had conceived with ovulation induction drugs within 6 months of regular menstrual cycles and had a spontaneous miscarriage at 8 weeks period of gestation. The second patient had a spontaneous conception after 9 months of the procedure and ended up with a subsequent premature labour at 34 weeks period of gestation.

\section{Discussion}

Human amniotic membrane grafting is a novel treatment modality to reduce inflammation and adhesion formation after hysteroscopic adhesiolysis. It has been postulated that the basalis layer of the endometrium harbours endometrial stem or progenitor cells, which are responsible for its regenerative capacity [7]. Inflammation may prevent the endometrium from regenerating due to the deposition of fibrotic tissue as fibrosis is triggered. [8]. But according to Nagori CB et al., autologous bone marrow stem cells placed in the uterus in severe Asherman's Syndrome, enabled regeneration of the endometrium sufficient to support a donor IVF embryo [9]. The intrauterine device (IUD) and an intrauterine Foley balloon have been studied and used to prevent adhesions after hysteroscopic procedures and Foley balloon has been found to yield better results. [10]. The use of amniotic membrane graft in cases of vaginoplasty has yielded remarkable results as the vagina is well formed without any evidence of stenosis [11]. Pregnancy outcomes in patients who received the graft needs to be explored further however, there are many confounding factors that could impact the pregnancy rate. In the present study we had two pregnancies and one live-birth following intrauterine grafting. Estrogen supplementation after lysis of intrauterine adhesions may be advantageous to increase the endometrial proliferation and prevent fibrosis [12]. Amniotic membrane use in ophthalmology has been proved to be an alternative for corneal and conjunctival reconstruction in many clinically challenging cases. The translational potential of an efficient and inexpensive method to prepare de-epithelialized HAM as a basement membrane scaffold for cell-based tissue-engineered treatments of ocular surface disorders has also been documented [13].

\section{Conclusion}

It can be concluded that based on this case-series there may be a utility for using human amniotic membrane intrauterine graft in a selective group of women to improve endometrial thickness while the functional aspects of the endometrium as demonstrated by successful pregnancy outcome. At present this work is being pursued at our institute to assess its proper utility on a larger scale.

\section{Authorship}

Dr. Siddhartha Chatterjee: Conception and design, analysis and interpretation of data; revising manuscript critically for important intellectual content

Dr. Bishista Bagchi: Drafting the article; acquisition of data, revising manuscript

\section{Dr. Arpan Chatterjee: Drafting of article, data collection}

Final approval of the version to be published given by all authors.

Agreement to be accountable for all aspects of the work in ensuring that questions related to the accuracy or integrity of any part of the work are appropriately investigated and resolved.

\section{Acknowledgments}

Miss Orphi Bhattacharya for formatting the manuscript

\section{References}

1. Yu D, Wong YM, Cheong Y, Xia E, Li TC (2008) Asherman syndrome-one century later. Fertil Steril 89: 759-779. [crossref]

2. Friedler S, Margalioth EJ, Kafka I, Yaffe H (1993) Incidence of post-abortion intrauterine adhesions evaluated by hysteroscopy--a prospective study. Hum Reprod 8: 442-444. [crossref]

3. Fedele L, Vercellini P, Viezzoli T, Ricciardiello O, Zamberletti D (1986) Intrauterine adhesions: Current diagnostic and therapeutic trends. Acta EurFertil 17: 31-37. [crossref]

4. Chen FP, Soong YK, Hui YL (1997) Successful treatment of severe uterine synechiae with transcervical resectoscopy combined with laminaria tent. Hum Reprod 12: 943-947. [crossref]

5. Newton JR, MacKenzie WE, Emens MJ, Jordan JA (1989) Division of uterine adhesions (asherman's syndrome) with the nd-YAG laser. Br J Obstet Gynaecol 96: 102-104. [crossref]

6. Amer MI, Abd-El-Maeboud KH (2006) Amnion graft following hysteroscopic lysis of intrauterine adhesions. J Obstet Gynaecol Res 32: 559-566. [crossref]

7. Rockey DC, Bell PD, Hill JA (2015) Fibrosis--A common pathway to organ injury and failure. N Engl J Med 373: 95-96 [crossref]

8. Gargett CE, Healy DL (2011) Generating receptive endometrium in asherman's syndrome. J Hum Reprod Sci 4: 49-52. [crossref]

9. Nagori CB, Panchal SY, Patel H (2011) Endometrial regeneration using autologous adult stem cells followed by conception by in vitro fertilization in a patient of severe asherman's syndrome. J Hum Reprod Sci 4: 43-48. [crossref]

10. Orhue AA, Aziken ME, Igbefoh JO (2003) A comparison of two adjunctive treatments for intrauterine adhesions following lysis. Int $J$ Gynaecol Obstet 82: 49-56. [crossref]

11. Chakravarty BN (1977) Congenital absence of the vagina and uterus - simultaneous vaginoplasty and hysteroplasty. Journal of obstetrics and gynaecology of India $627-632$.

12. Farhi J, Bar-Hava I, Homburg R, Dicker D, Ben-Rafael Z (1993) Induced regeneration of endometrium following curettage for abortion: A comparative study Hum Reprod 8: 1143-1144. [crossref]

13. Bandeira F, Yam GH, Fuest M, Ong HS, Liu YC (2019) Urea-De-Epithelialized Human Amniotic Membrane for Ocular Surface Reconstruction. Stem Cells Transl Med 8: 620-626. [crossref]

\section{Citation:}

Siddhartha Chatterjee, Bishista Bagchi and Arpan Chatterjee (2020) Treating uterine synechiae with human amniotic membrane graft. Integr Gyn Obstet J, Volume 3(1): 1-2. 